\title{
A INTERSEMIOSE TEXTO-HISTÓRIA-CINEMA NA MINISSÉRIE ROMA DA HBO
}

\author{
THE TEXT-HISTORY-CINEMA INTERSEMIOSIS IN HBO'S ROME
}

\author{
João Batista Toledo Prado \\ UNESP - Universidade Estadual Paulista (FCLAr)
}

\begin{abstract}
RESUMO: Entre agosto de 2005 e março de 2007, foram exibidas as duas temporadas da premiadíssima minissérie ROMA, com 12 e 10 episódios respectivamente, no canal de TV por assinatura da Home Box Office (HBO). Com história assinada por vários roteiristas e diretores, coprodução da própria HBO (EUA) e BBC (Reino Unido), com apoio da RAI (Itália), e filmada em múltiplas locações, mas principalmente nos estúdios cinematográficos de Cinecittà, em Roma, célebres por terem sido sede também da obra de Federico Fellini, a minissérie retrata, na primeira temporada, a conquista das Gálias, empreendida pelo gênio militar de Caio Júlio César, e a trajetória política que o fez acumular poder de tal forma a dividir os cidadãos romanos em duas facções, uma que o apoiava, outra que o combatia, centrada sobretudo na figura do general Cneu Pompeu Magno; a segunda temporada mostra o período da guerra civil que sucedeu ao assassinato de César, com a ascensão ao poder de seu sobrinho, filho adotivo e único herdeiro, Caio Otávio Augusto, após ter sobrepujado seus rivais bem como seus aliados no triunvirato que se havia formado para perseguir e punir os assassinos de César. Tais fatos são sobejamente conhecidos e povoam a mente e a imaginação de todos os minimamente escolarizados. Assim mesmo, a série da HBO inovou não apenas pelo talento de roteiristas, diretores e atores, nem somente pelos efeitos visuais, locações, vivacidade e grandiosidade das cenas históricas - afinal, "filmes de época" em geral fazem o mesmo - mas também pela (re)construção de eventos históricos a partir da ótica de uma dupla de protagonistas dos quais pouco se conhece: os centuriões Tito Pullo (ou Pulão) e Lúcio Voreno, únicos soldados nomeados por César na obra Comentários sobre a Guerra das Gálias (Commentarii de Bello GallicoV.44). Por isso, a ficcionalização dos eventos levou em conta também diversos dados de civilização romana dispersos em obras historiográficas e que fazem parte do conhecimento moderno de cultura material, resultando num seriado de TV com estética fílmica de rara beleza e criatividade. A partir do levantamento de dados textuais, históricos e culturais reunidos na recriação fílmica do seriado, bem como da distância que caracteriza o espaço criativo na dimensão do intervalo entre eles, este trabalho objetiva salientar dois momentos privilegiados das estratégias visual e narrativa do seriado: a sequência dos créditos de abertura e as cenas finais da primeira temporada de Roma da HBO.
\end{abstract}

PALAVRAS-CHAVE: Relações Intersemióticas; Seriado Roma (HBO); De Bello Gallico; Cultura Material; Sequências de abertura e final.

ABSTRACT: From August 2005 to March 2007, the two seasons (with 12 and 10 episodes respectively) of the award winning miniseries HBO's ROME were aired by the Home Box Office 
(HBO) channel. With screenplay signed by various writers and directors, the TV series was a coproduction of HBO (USA) and BBC (UK) with support from RAI (Italy), and the show was filmed in multiple locations, but mainly in Cinecittà Film Studios in Rome, very famous for having been headquarters also for Federico Fellini's movies. In the first season, the miniseries depicts the conquest of Gaul, made by the military genius of Gaius Julius Caesar, and the political trajectory that made him accumulate power to such an extent that this divided Roman citizens into two factions, one supporting and the other opposing him, the latter focused mainly on the historic figure of General Gnaeus Pompey Magnus. The second season shows the period of civil war following the assassination of Caesar, and the future rise to power of his nephew, adopted son and sole heir, Gaius Octavian Augustus, who was destined to overcome his rivals as well as their allies in the triumvirate that had been formed to pursue and punish Caesar's assassins. These facts are well known and usually crowd the mind and imagination of every minimally educated person. The HBO series broke new ground not only for the talent of its writers, directors and actors, not only for its visual effects and locations nor for the vibrancy and grandeur of historical scenes - after all, "historical movies" in general do the same - but it has done so also by the (re)construction of historical events from the perspective of a pair of protagonists of whom too little is known: the centurions Titus Pullo and Lucius Vorenus, who are the only low-rank soldiers mentioned by Caesar in his book Commentaries on the Gallic War (Commentarii de Bello Gallico V.44). Thus, the fictionalization of events also took into account several Roman civilization data which were scattered through historical sources and also those that belong to the modern knowledge of material culture, resulting in a TV series whose filmic aesthetics has rare beauty and creativity. From the survey of textual, historical and cultural data put together in this film, as well as the distance featuring the creative space in the dimension of the gap between them, this paper aims to highlight two pivotal moments of visual and narrative strategies of the show: the opening credits footage and the final scenes of the first season of HBO's Rome.

KEYWORDS: Intersemiotic Relations; HBO's Rome TV series; De Bello Gallico; Material Culture; Opening and final footages.

Começamos com a ideia de contar a história do ponto de vista de dois soldados de infantaria, Lúcio Voreno e Tito Pulo, os dois únicos soldadosrasos mencionados por César em seus Comentários sobre as Guerras da Gália. Percebi que sua perspectiva de transeuntes da classe trabalhadora era a chave. E se fizéssemos a série como se fosse um drama urbano contemporâneo? Como se tivesse sido filmado nas verdadeiras ruas da Roma republicana? Não a Roma de mármore branco e veludo vermelho dos velhos filmes de espada-e-sandálias, mas a colorida, caótica, congestionada e suja cidade que ela era: um mundo de grande beleza e miséria abjeta. E se mostrássemos os romanos do modo como eles realmente eram - em toda sua chocante glória pagã - sem julgá-los e sem impor-lhes uma moralidade moderna? E se tentássemos criar um drama de TV que um cidadão romano do fim da República poderia assistir, reconhecer e apreciar?

(HELLER, 2007, p. 6) ${ }^{1}$

\footnotetext{
1 "We started with the notion of telling the story from the perspective of two foot soldiers, Lucius Vorenus and Titus Pullo, the only two rank-and-file soldiers mentioned by Caesar in his Commentaries on the Gallic Wars. I realised that their working-class, 'street' perspective was the key. What if we made the show as if it were a contemporary urban drama? As if it were shot on the actual streets of Republican Rome? Not the white marble and red velvet Rome of old sword-and-sandal movies, but the colorful, chaotic, crowded, dirty city that it was: a world of great beauty and abject squalor. What if we showed the Romans the way they really were - in all their shocking pagan glory - without judging them and without imposing a modern morality on them? What if we tried to create a TV drama that a Roman citizen of the late Republic might watch and recognize and enjoy?" (HELLER, 2007, p. 6).
} 
Entre agosto de 2005 e março de 2007, foram exibidas as duas temporadas da premiadíssima minissérie ROMA (Rome), com 12 e 10 episódios respectivamente, no canal de TV por assinatura da Home Box Office (HBO). Com história assinada por vários roteiristas (Bruno Heller, John Milius, William J. MacDonald etc.), vários diretores (Michael Apted, Tim van Patten, Allen Coulter, Allan Taylor etc.), co-produção da própria HBO (EUA) e BBC (Reino Unido), com apoio da RAI (Itália), e filmada em múltiplas locações, mas principalmente nos estúdios cinematográficos de Cinecittà, em Roma, célebres por terem sido sede também da obra de Federico Fellini, a minissérie retrata, na primeira temporada, a conquista das Gálias, empreendida pelo gênio militar de Caio Júlio César, e a trajetória política que o fez acumular poder de tal forma a dividir os cidadãos romanos em duas facções, uma que o apoiava, outra que o combatia, esta centrada sobretudo na figura do general Cneu Pompeu Magno; a segunda temporada mostra o período da guerra civil que sucedeu ao assassinato de César, com a ascensão ao poder de seu sobrinho, filho adotivo e único herdeiro, Caio Otávio Augusto, após ter sobrepujado seus rivais bem como seus aliados no triunvirato que se havia formado para perseguir e punir os assassinos de César. Tais fatos são sobejamente conhecidos e povoam a mente e a imaginação de todos os minimamente escolarizados, assim mesmo, a série da HBO inovou não apenas pelo talento de roteiristas, diretores e atores, nem somente pelos efeitos visuais, locações, vivacidade e grandiosidade da reconstituição histórica - pelo que tratar-se-ia de apenas mais um "filme de época" - mas também pela (re)construção de eventos históricos a partir da ótica de uma dupla de protagonistas dos quais pouco se conhece: os centuriões Tito Pullo (ou Pulão) e Lúcio Voreno, únicos soldados nomeados por César na obra Sobre a Guerra das Gálias (De Bello GallicoV.44). Por isso, a ficcionalização dos eventos levou em conta também diversos dados de civilização romana dispersos em obras historiográficas e conhecimento moderno de cultura material, resultando num filme para TV de rara beleza e criatividade. Este trabalho objetiva mostrar a distância entre o dado textual e histórico e sua recriação fílmica, de maneira a delimitar e caracterizar o espaço de criação na dimensão do intervalo entre eles.

\section{Apenas dois homens do povo.}

O general romano Caio Júlio César notabilizou-se não apenas por suas bem sucedidas campanhas militares nem somente por seu projeto de poder, que quase o levou a ser o primeiro imperador de Roma, mas, sobretudo nas Letras Clássicas, fê-lo também pela autoria dos Commentarii De Bello Gallico e também dos Commentarii De Bello Ciuili (“Comentários da Guerra das Gálias" e "Comentários da Guerra Civil”), livros que, a um só tempo, auxiliaram a definir a imagem pública de César e sua reputação de grande combatente e eficiente general - o que, sem dúvida, serviu para abrir caminho para seu projeto de poder e também passou a figurar como um parâmetro de qualidade linguística e estilística para a prosa do período clássico das letras latinas.

Em seu De Bello Gallico (Sobre a Guerra das Gálias), César menciona o nome de muitas personalidades históricas, em especial o dos chefes das tribos gaulesas com que seus romanos travavam batalhas, bem como o daqueles romanos ilustres que atuavam como seus comandantes-em-chefe. No livro $\mathrm{V}$, porém, ele faz a única menção nominal da obra a dois soldados de baixa patente, os centuriões - i.e., líderes de uma centúria, ou destacamento de cem soldados - Tito Pulo (ou Pulão) e Lúcio Voreno. Ambos são mencionados tanto pela qualidade intrínseca de sua coragem, como aparentemente também pelo potencial valor moral de uma rivalidade absoluta que soube converter-se em solidariedade em momentos de crise, como se depreende da leitura da passagem a seguir: 


\section{CAESAR - De Bello Gallico}

\section{César - Sobre a Guerra das Gálias}

(Livro 5.44)
Erant in ea legione fortissimi uiri centuriones qui iam primis ordinibus adpropinquarent, Titus Pullo et Lucius Vorenus. $\mathrm{Hi}$ perpetuas inter se controuersias habebant, uter alteri anteferretur, omnibusque annis de loco summis simultatibus contendebant. Ex his Pullo, cum acerrime ad munitiones pugnaretur, 'quid dubitas' inquit 'Vorene? Aut quem locum tuae probandae uirtutis exspectas? hic dies de nostris controuersiis iudicabit'. Haec cum dixisset, procedit extra munitiones quaque hostium pars confertissima est uisa, inrumpit. Ne Vorenus quidem sese tum uallo continet, sed omnium ueritus existimationem subsequitur. Mediocri spatio relicto Pullo pilum in hostes inmittit atque unum ex multitudine procurrentem traicit. Quo percusso exanimatoque hunc scutis protegunt hostes, in illum uniuersi tela coniciunt neque dant progrediendi facultatem. Transfigitur scutum Pulloni et uerutum in balteo defigitur. Auertit hic casus uaginam et gladium educere conanti dextram moratur manum impeditumque hostes circumsistunt. Succurrit inimicus illi Vorenus et laboranti subuenit. Ad hunc se confestim a Pullone omnis multitudo conuertit; illum ueruto transfixum arbitrantur. Vorenus gladio rem comminus gerit atque uno interfecto reliquos paulum propellit; dum cupidius instat, in locum inferiorem deiectus concidit. Huic rursus circumuento subsidium fert Pullo, atque ambo incolumes compluribus interfectis summa cum laude intra munitiones se recipiunt. Sic fortuna in contentione et certamine utrumque uersauit, ut alter alteri inimicus auxilio salutique esset neque diiudicari posset, uter utri uirtute anteferendus uideretur.
Havia naquela legião homens bravíssimos: os centuriões Tito Pulo e Lúcio Voreno, que já se aproximavam das mais altas patentes. Eles tinham entre si disputas intermináveis sobre qual deles deveria ser preferido ao outro e, todos os anos, competiam pelo mesmo posto com a maior rivalidade. Desses dois, Pulo, quando estava lutando renhidamente junto às paliçadas, disse: "Por que hesitas, Voreno? Ou aguardas que outro lugar para provar teu valor? Este dia decidirá nossas disputas". Apenas dissera tais coisas, já avança para fora das paliçadas e ataca no lado em que o destacamento inimigo the pareceu o mais cerrado. Não apenas Voreno não se mantém mais junto à trincheira mas, temendo o juízo dos companheiros, segue logo atrás. Percorrido metade do caminho, Pulo lança seu dardo-pilo contra os inimigos e trespassa um que vinha correndo da multidão. Trespassado e quase já sem vida, os inimigos protegem-no com seus escudos e todos juntos atiram lanças contra Pulo, não lhe dando nem chance de voltar. O escudo de Pulo é transpassado, e um dardo crava-se em seu cinturão. Tal acontecimento desvia a bainha, retarda sua mão direita ao tentar sacar a espada, e os inimigos cercam-no enquanto ele está embaraçado. Presta-lhe auxílio e corre em socorro daquele em dificuldade o rival Voreno. Toda a turba volta-se logo de Pulo para ele, pois julgamno trespassado pelo dardo. No corpo a corpo, Voreno domina a situação com sua espada e, tendo morto um deles, repele os restantes um pouco; quando investe mais avidamente, cai lançado em um ponto mais baixo. A seu turno, Pulo leva reforço àquele que se via cercado, e, depois de mortos vários, ambos se reconduzem incólumes para dentro das fortificações, com o maior louvor. Assim, no combate e na rivalidade a fortuna voltou-se ora a um ora a outro, de modo que um fosse para o outro auxílio e salvação, e não se pudesse julgar qual deles parecesse dever ser preferido ao outro em bravura.

Disponível em: http://seer.fclar.unesp.br/casa 
Como se pode verificar, os dois centuriões nomeados ganharam espaço nos Commentarii de César por constituírem exemplo de superação de rixas pessoais diante da necessidade de enfrentar um perigo comum, o que parece ilustrar muito bem o espírito de combate romano, aparente intenção narrativa da recolha do fato mencionado.

É interessante notar que a história das conquistas de Roma contou com a capacidade de coordenação de tropas militares, sempre comandadas por estrategistas de peso, de que o próprio César é, provavelmente, a figura mais insigne, mas, entretanto, não com heróis individuais: a força bélica de Roma sempre deveu-se mais à capacidade conjunta de combate que à ação de guerreiros isolados, razão pela qual os relatos históricos invariavelmente destacam a figura de grandes comandantes como César, mas não a bravura de soldados unitários. Há, sim, relatos de bravura individual em momentos muito recuados da história romana, como o episódio de bravura em combate dos Horácios romanos lutando contra os Curiácios da rival Alba Longa, e o de Múcio Cévola, ambos narrados por Tito Lívio (Ab urbe condita, 1.24-26 e 2.12-3, respectivamente), e até mesmo histórias de atos de coragem feminina, como a de Lucrécia (Tito Lívio, Ab urbe condita, 1.57-60) e a de Clélia (T. Lívio, Ab urbe condita, 2.13; V. Máximo, Factorum ac dictorum memorabilium, 3.2.2), mas eles correspondem claramente à necessidade de forjar modelos cívicos, que veiculem valores morais e guerreiros que a aristocracia dominante esperava ver praticada pelo conjunto da sociedade romana, pouco importando sua fidedignidade histórica, valor, aliás, marcadamente moderno, de vez que a história grega e romana constituem mais um gênero literário que uma tentativa precoce de cientificismo.

Não é nada impossível que Voreno e Pulo tenham tido existência histórica real e que, mesmo na rivalidade, tenham protagonizado a história de bravura relatada no De Bello Gallico, mas César pode ter feito fazer questão de mencioná-los ali, menos por perseguir algum difuso e anacrônico conceito de fidelidade factual que por ver no fato, se é que existiu, uma renovação de matrizes morais modelares, bem como uma oportunidade para que a referida passagem de seus Commentarii se alinhassem com o venerável repertório das lendas dos primeiros tempos de Roma, sobretudo as do início da República, estabelecendo, ao mesmo tempo, uma relação dialética entre tais narrativas e seus próprios relatos de batalha, relação que, no contexto literário de meados do século I a.E.C., se resolve no conceito de emulação, nesse caso, nas lendas fundacionais dos primeiros tempos da Vrbs primitiva.

De todo modo, o fato é que as personalidades do Pulo e do Voreno encarnados na série Roma da HBO emergiram desse breve relato apenas, e por aí se pode avaliar a dimensão da empreitada narrativa arrostada por Bruno Heller e os demais roteiristas da série sob seu comando. É também curioso que, a julgar pelo contraste entre o tom do início das intervenções diretas de Pulo, e também pelo modo como é descrita a reação de Voreno, coagido como fora a abandonar a segurança das trincheiras por "temer o juízo de todos", ou seja, pelo temor de parecer menos valente que Pulo e, assim, de ver depreciado o estatuto militar e social que seus pares lhe atribuiriam, o César-narrador parece inclinar-se mais a favor de Voreno que de Pulo. No seriado Roma, entretanto, é Pulo, eleito senador e atuando como protetor de César, que encarna a figura do soldado que merece as graças e os favores políticos do general, em detrimento de Voreno, que, aliás, é retratado como subalterno hierárquico de Pulo, o que distancia, nesse ponto, a ficção televisiva do fato textual veiculado pela passagem do De Bello Gallico que se acaba de examinar.

Muitas liberdades desse tipo foram tomadas na série da HBO, aliás. Apenas para citar alguns exemplos: a) à época dos eventos históricos retratados em Roma da HBO, o 
Egito fazia parte do mundo helenístico criado pelas conquistas do macedônio Alexandre Magno, e, por isso, hábitos, comportamentos e indumentária de seus habitantes eram mais gregos, sobretudo, sem dúvida, na vida palaciana da corte dos Ptolomeus, entretanto, a série mostra-os ainda com muitas características e traços do Egito antigo; b) a caminho de encontrar-se com César, Cleópatra procura conhecer as feições do general romano contemplando sua efígie na superfície em uma moeda que, entretanto, só seria cunhada anos depois de sua relação com ele; c) a irmã do jovem Octaviano, que haveria de tornar-se o primeiro imperador de Roma após o assassínio de César, e que era seu sobrinho-neto e filho por adoção, recita alguns versos da Eneida durante uma festa, entretanto, a obra máxima de Virgílio só teria sido composta anos mais tarde, já sob o governo de Otacviano e por sua encomenda - claro que, aí, há possivelmente uma intenção narrativa de excitar o público douto da série, por meio de um jogo intertextual que dialoga, antecipa e forja um signo da glória futura que aguarda o jovem Octaviano, cuja chave enunciativa poderia traduzir-se numa sugestão oracular; d) quando César é assassinado, Octaviano aparece junto da mãe Ácia, sendo ameaçada pela ex-amante de César, Servília, porém, na época, ele estava numa campanha militar na Ilíria, região onde hoje se acham a Romênia, Croácia, Sérvia, etc.; e) trazendo à baila reminiscências de seu passado, o centurião Tito Pulo confessa a Irene, sua escrava e futura esposa, que ele também havia nascido escravo, porém, pelas leis da época, somente romanos livres de nascimento poderiam alistar-se no exército e ocuparem postos como o de centurião.

É evidente que liberdades como essas não conspurcam nem subtraem ao seriado seus méritos fílmicos e de acurácia arqueológica, afinal, trata-se patente e claramente de uma obra de ficção inspirada na história dos eventos romanos conhecidos, e não de um documentário. Como lembra o co-produtor e consultor histórico da série:

Roma não é cem por cento precisa em termos históricos e nunca pretendeu ser. Ela é, afinal, um drama e não um documentário, distinção sobre a qual fui muito claro, desde o início. Ela foi inspirada por eventos reais do período final da República Romana - e permaneceu bem próxima deles - mas ficcionalizou-os, preencheu algumas lacunas, e forjou algumas novas e imaginativas conexões. (STAMP, 2007, p. 8) ${ }^{2}$

Uma vez que Roma é claramente um drama feito para a TV, convém refletir acerca do que isso acarreta em termos do enquadramento genérico da obra bem como de sua propalada originalidade.

\section{O novo e o serial.}

Em seu ensaio sobre séries de TV, Umberto Eco (1989) lembra que, desde o Maneirismo, a era moderna passou a aferir qualidade artística com base num conceito de originalidade, que implica surpreender as expectativas do destinatário, renovando suas experiências e visão de mundo (ECO, 1989, p. 120). Confrontada, porém, com o fenômeno da produção em série dos meios de comunicação de massa, a estética moderna passou a execrar a

\footnotetext{
2 "Rome is not one hundred percent historically accurate and it was never meant to be. It is, after all, a drama, not a documentary, a distinction I was very clear about from the beginning. It was inspired by - and stayed close to - the actual events of the late Roman Republic, but it fictionalized them, filled it in some gaps, and made some imaginative new connections."(STAMP, 2007, p. 8).
} 
serialidade da indústria cultural, considerada mais deletéria que a da indústria de bens de consumo (ibidem). Isso porque, em particular nos meios de comunicação de massa, um mesmo conteúdo pode ser mascarado de forma intencional para apenas aparentar diferença (ibidem, p. 121), caso em que se inclui o seriado de televisão, considerado pela alta cultura como um caso de serialidade fechada e "degenerada", em oposição a uma serialidade "aberta e honesta", como a da indústria de artesanato, por exemplo (ibidem).

Eco não descura considerar que muitos consumidores de séries, em geral, são capazes de reconhecer a matriz serial, o modelo que se repete, ainda que se apresente como novidade, e que é provável que seja esse mesmo o fator que os leva a consumi-las (ibidem, p. 122). Ele propõe distinguir uma tipologia da serialidade dos meios de massa, em que se reconhecem (ibidem, p. 122-5): a) a retomada ou continuação, em que determinados arquétipos culturais - um tema - são recobertos com diverso revestimento figurativo, como no caso do bem versus mal, em Guerra nas Estrelas, ou o tema bíblico do messias, em Superhomem.; b) o decalque, que se caracteriza por tomar os componentes de uma estrutura fabular de sucesso - suas situações narrativas ou seu estilo - e reformular componentes para recontá-la (ambiência e personagens, por exemplo), geralmente procurando ocultar esse fato do consumidor, como acontece na maior parte dos faroestes; há também uma forma explícita de decalque, que são os inúmeros casos de remake; c) a saga, cujo traço distintivo é a evolução no tempo, com uma personagem ou genealogia de personagens que se ligam entre si, experimentando eventos sempre novos e ilustrando a passagem do tempo e o envelhecimento inexorável, que podem dar-se em linha contínua ou em esquema de árvore, como um antepassado que origina vários núcleos narrativos, apoiados em descendentes e afins; contudo, sob a fachada de evolução temporal, as diferentes personagens viverão sempre as mesmas situações (disputa por riqueza e poder, vitória, derrota, amor, ódio, adultério, etc.), como ocorre com a série Dallas da TV; com isso, a saga acaba por negar a historicidade mais elementar, sendo, assim, uma forma dissimulada de série; d) a série propriamente dita, cujo traço principal é a reprodução de uma mesma estrutura narrativa, em que se propõem situações e personagens fixos, com personagens secundários que mudam, se alteram ou desaparecem, justamente para criar a impressão de novidade que justifica consumir episódios sempre novos, como acontece nos romances e seriados policiais e nas sitcoms, verdadeiro pilar de sustentação da indústria do entretenimento televisivo, sobretudo nos EUA; ocorre que o reencontro com o elemento conhecido parece gerar um prazer que advém da satisfação de uma "necessidade infantil mas, nem por isso doentia, de ouvir sempre a mesma história, de consolar-se com o retorno do idêntico, superficialmente mascarado" (ECO, 1986, p. 123), por isso, a série compraz o espectador que, reconhecendo consciente ou inconscientemente os componentes da estrutura, se torna capaz de prever desdobramentos narrativos (ibidem, p. 124).

O semiólogo italiano propõe também distinguir variantes estruturais nas séries, tais como: d.1) a das histórias em flash-back, que são capazes de descobrir novas oportunidades narrativas para as mesmas personagens e situações; d.2) as séries em loop, que fazem as personagens viverem as mesmas situações habituais mas em seu passado (vejam-se as intermináveis sequências dos quadrinhos de Superboy ou todo o seriado Smallville, por exemplo), movimento que por vezes provoca o paradoxo de personagens terem mais passado que futuro e, mesmo assim, esse passado não pode alterar seu presente mítico, que é como ele foi dado a conhecer ao destinatário em primeiro lugar; d.3) as séries em espiral, em que nada ou muito pouco acontece, mas a personagem principal torna-se mais profunda e complexa a cada novo episódio, como ocorre nas tiras de Charlie Brown, de Charles Schulz, e nas de Mafalda, de Quino; d.4) séries de personagens de ator, em que predominam personagens- 
tipo, encarnadas por atores especializados em produzir os mesmos esquemas comportamentais; nesse caso, mesmo empenhando-se em viver histórias diferentes, eles são enquadrados nas mesmas estruturas narrativas pelo público, que reconhece o modelo de atuação e dele se compraz (ibidem, p. 124-5), o que ocorre, por exemplo, com as personagens de cowboy de John Wayne, as de tipo "durão" de Charles Bronson e as cômicas de Jim Carey.

Sabe-se que os textos definem dois tipos de leitores ideais: o de primeiro nível, a que poderia chamar um leitor ingênuo, que é conduzido mais ou menos passivamente pela narrativa, sofrendo as reações que as estratégias empregadas programaram para ele, e o de segundo nível, a que chamaria um leitor crítico, que se entretém precisamente com a volta do mesmo, mas por perceber as estratégias de variação narrativa empregadas para mascarar a repetição (ECO, 1986, p. 129), as quais, em certos momentos, chegam a quebrar a expectativa de desfechos previsíveis.

O que ocorre é que parece haver uma relação dialética entre repetição e inovação, que admite formas e graus infenitesimais de manifestação, de acordo com o lugar e o momento em que dada cultura sedimenta sua validação, e é isso que forja a estética das formas seriais (ibidem, p. 130-1). É preciso lembrar que formas artísticas seriais e recorrentes existem na história europeia do espetáculo e da performance desde há muito (pense-se, por exemplo, nas renovadas encenações teatrais, entre gregos e romanos, de mitos muitíssimo conhecidos), e, no presente, há também aquelas validadas pela cultura dita "alta" (por exemplo, as variações de tema na música erudita, como as Variações Goldberg para cravo, de Bach). Excelência ou banalidade da repetição dependerão, portanto, do tipo de pacto proposto pelo texto com seu leitor ideal, ingênuo ou crítico.

Por tais considerações, vê-se que, a despeito de chamar-se série ou minissérie, Roma da HBO é, de fato, antes uma saga, pois está centrada na sucessão de fatos históricos que implicam mudanças e, de fato, as personagens ali evolucionam, embora também se constate que, ao César morto, sucede um Octaviano que terá de lidar com situações de disputa de poder, traição, possibilidade de vitória ou derrota, amor, ódio, da mesma maneira que seu predecessor, embora som resultados diferentes, e o mesmo vale para as personagens menos proeminentes do poder aristocrático romano, assim como para as personagens humildes, Pulo e Voreno. Trata-se, portanto, na concepção de Eco, de uma série disfarçada, e a genialidade da realização da HBO em parceria com a BBC consiste, por um lado, em perceber o potencial daquele período crítico da história romana para produzir o mesmo tipo de apelo conferido pelas séries - ou sagas - modernamente encenadas para a TV, fato que, sem dúvida, se origina em decisões meramente comerciais, mas que determinarão igualmente a capacidade de uma produção investir em talentos especializados, capazes, por exemplo, de produzir a autenticidade de cultura material vista em Roma. Por outro lado, há o ponto de vista artístico, que dependerá da densidade e profundidade do contrato com o leitor do texto, que, no presente caso, se estabelece com um leitor crítico de elevado grau, não apenas por dialogar de modo intenso com o intertexto da história oficial conhecida ${ }^{3}$, mas sobretudo por propor paralelismos que propiciam múltiplos e variados níveis de leitura.

As duas temporadas da série Roma contêm 22 episódios de aproximadamente 55 minutos de duração, desenrolando-se por mais de 20 horas, e seria impossível considerá-la em sua totalidade neste espaço. Para ilustrar a engenhosidade a que se aludiu há pouco, serão, por isso, analisados apenas dois momentos, mais precisamente a riquíssima abertura sempre repetida no início de cada episódio do seriado e as cenas finais do último episódio da primeira

\footnotetext{
${ }^{3}$ É preciso lembrar aqui “a tendência, principalmente nos trabalhos críticos das linguagens que se integram num filme, seguida pelos pesquisadores mais sérios, de buscar sempre as relações de intertextualidade fundadoras dos traços estilísticos mais singulares de uma obra." (PEÑUELA CAÑIZAL, 2004, p. 13, nota 2).
}

Disponível em: $\underline{\text { http://seer.fclar.unesp.br/casa }}$ 
temporada, momento em que a história culmina com o assassínio de César na Basílica de Pompeu.

\section{Ab Ouo (Desde o início)}

Cada um dos episódios de Roma começa sempre com a mesma sequência exibindo os créditos de abertura da série, que principiam logo depois da tradicional imagem de TV fora do ar, que é a marca registrada das produções seriais da HBO. Em seguida, surge uma montagem de 1,5 minuto de duração, que principia com uma animação que se vai alternando com cenas de transeuntes em suas ocupações diárias, perambulando pelas ruas de Roma. As animações dão vida e movimento a figuras parietais, que representam mosaicos e grafitos romanos, do tipo encontrado principalmente em Pompeia.

A primeira figura a aparecer é um mosaico com uma caveira dependurada em uma trave em forma de "A", de cujos vértices pendem dois cordames com objetos nas pontas. A caveira apoia-se nas asas de uma borboleta que, por sua vez, ameaça voar de sobre uma roda, e o conjunto todo move-se para a esquerda e para a direita, em equilíbrio precário. A trave é, de fato, um nível (instrumento de construção); o crânio, o peso nivelador; a borboleta, a alma; a roda, a Fortuna; o conjunto é uma representação alegórica da morte como grande niveladora do mundo, porque, dependendo dos movimentos da roda, anulam-se as diferenças de classe: os objetos laterais são, de um lado, um cetro envolto em púrpura, emblema de riqueza, de outro, o alforje e a vara de mendigo, representando a pobreza. Trata-se de um tema helenístico que permaneceu na cultura arquitetônica latina: esse mosaico, intitulado Memento Mori (Lembra-te de que hás de morrer) foi encontrado em um triclinium (sala de jantar) em Pompeia e hoje acha-se no Museu de Nápoles ${ }^{4}$. É assim que começa a ser engenhosamente produzido o efeito de sentido autenticidade da série e, ao mesmo tempo, introduz-se um importante componente temático: a série tratará da oscilação da Fortuna e da morte.

O olhar do espectador é, então, conduzido num travelling para dentro da cavidade do olho esquerdo do crânio - claro convite a ver para além da morte, isto é, penetrando no passado sombrio - mas, da escuridão resultante, passa-se a um rápido deslocamento de câmera que vai do céu, entrevisto entre dois prédios, para um arco sobre uma rua de Roma - possível metamorfose da órbita do olho da caveira - por onde passam três atores reais, representando habitantes da Vrbs. A câmera oscila ligeiramente entre foco e meio-foco, de forma que as figuras humanas parecem envoltas em uma espécie de bruma que lhes tolda as feições, afinal, trata-se de pessoas comuns, que registros históricos não privilegiaram. Acompanhando a que ocupa o primeiro plano, um rápido corte mostra-a passando, ainda desfocada, sobre o fundo de uma parede, de onde se destacam nitidamente uma mancha vermelha horizontal com linhas brancas de giz que representam, à esquerda, os arcos de um aqueduto ou de um circo, à direita, a figura animada de uma gladiador em luta com quatro oponentes menores - talvez pigmeus. Aqui, o fundo e as animações serão, na sequência toda, muito mais nítidos que as figuras humanas, para novamente infundir a sensação de autenticidade histórica. Além disso, outro tema insinua-se: o dos combates sangrentos e espetáculos cruentos, de que a mancha vermelha é eloquente sinal.

\footnotetext{
4 Mosaico "Memento mori", entre 30 a.E.C. e 14 d.E.C. Inv. No. 109982. Nápoles, Museo Archeologico Nazionale. Cf. http://ancientrome.ru/art/artworken/img.htm?id=1755, acesso em 16/10/2012.
} 
Mais um corte, outros passantes desfocados e nova parede, agora com figuras masculinas desenhadas em vermelho, que tomam nos ombros e raptam figuras femininas, desenhadas em branco, sobre um chão de linhas amarelas e umas poucas casas tracejadas em azul, sinal de que o mundo dos grafitos começa a ganhar cor, destaque e vivacidade; sobre o conjunto divisam-se, pela primeira vez, inscrições (tituli) em grafitos, mas, como não é possível decifrá-las, seu significado parece sugerir apenas escrita antiga romana, exótica e sem sentido, o que instiga a curiosidade e o desejo do espectador de vê-las reveladas (cf. HAYNES, 2009, p. 58), assim como de todo o exótico mundo que a vitrine dos créditos de abertura permite entrever.

$\mathrm{Na}$ cana seguida, ao lado de uma porta azul, veem-se uma mulher nua, desenhada em branco, e um minotauro grená, com contornos brancos e olhos amarelos, derramando sobre ela uma ânfora de um vinho que escorre sobre seu corpo, fazendo com que ela se banhe. Do lado direito e na vertical, lê-se a primeira palavra nítida e traduzível, natura ("natureza"), como a sugerir o gozo pleno da sensualidade sem peias, da maneira que a natureza insufla no homem.

Depois, numa rápida sequência de cortes pelas paredes que ladeiam as estreitas e escuras ruas da cidade, sucedem-se os grafitos de um homem que tenta puxar com corda um touro vermelho empacado, pelos quais passam, em rápida sucessão da esquerda para a direita, cavaleiros e carroceiros amarelos montados em cavalos azúis, que viajam de um trecho a outro pelas paredes da cidade, bem como por outras palavras em grafitos ilegíveis. Quando desaparecem, surge uma parede em que se desloca, da direita para a esquerda, outro cavaleiro azul, tracionando o que parece ser a cabeça de algum animal, e vai deixando um rastro de tinta vermelho-sangue no trajeto. A promessa, aqui, é de ação citadina e, novamente, espetáculos cruentos.

Outro corte, nova parede: desenhado realisticamente e com vários detalhes ao lado de uma janela de onde pende uma gaiola de pássaro, um legionário romano usando uma cabeça de javali por capacete, signo da campanha das Gálias, acompanha um passante com o olhar, o que consiste na primeira das raras interações das figuras em grafito com o mundo "exterior" dos atores-transeuntes. O interessante é o paralelismo entre a figura humana, pela primeira vez nitidamente desenhada, com o ato de olhar, que representa metaforicamente o espectador da série, numa promessa de que o realismo será tão intenso a ponto de ele conseguir experimentar o mundo representado na série. Não por outro motivo, o corte seguinte não traz grafitos animados, mas a imagem real de uma cabeça de antílope, pintada e dependurada numa parede como objeto de decoração, o que acentua a expectativa de que será possível testemunhar e experimentar exotismos.

$\mathrm{Na}$ parede seguinte, da direita para a esquerda, três gansos excitados esvoaçam sobre um muro vermelho, como cães de guarda a defender algum território, e leem-se as palavras populus (povo) e futuimus, $1^{\mathrm{a}}$ pessoa do plural do presente ou do perfeito do verbo futuere, termo chulo e popular para assinalar relações sexuais com uma mulher, além de outras palavras ilegíveis. Em seguida, passa-se a uma parede em que há apenas quatro figuras humanas caminhando de costas para o observador, da esquerda para a direita, mas crescem em relevo e significação os tituli, pois agora lê-se nobilitas miseria nostra, i.e., "nobreza (ou aristocracia), a nossa miséria" (e a palavra magnum, "grande", que não se sintagmatiza aqui), o que insere o componente de tensão social e de luta de classes.

Em seguida, nas duas laterais que ficam entre três janelas, duas figuras, uma feminina e outra masculina, vêm correndo do fundo para o primeiro plano; sob ela, lê-se Carcus Spedusam amat ("Carco ama Espedusa"), sob ele, Et Prethri, que talvez seja o nome de outro possível amante, o que sugere a experiência do triângulo amoroso. Na parede 
seguinte, aparece o único grafito figurado estaticamente, um gladiador em cima de uma frase de onde só se lê uictoria ("vitória"); mais abaixo, uma coluna e três mulheres nuas que parecem portar chicotes de tecido vermelho, que agitam à passagem de um homem nu, que parece ser um dançarino. Novamente, aqui, a promessa de novos espetáculos e hábitos culturais exóticos. Lê-se abaixo do conjunto todo, a palavra pax ("paz"), assim como a rápida parede seguinte mostra um homem estilizado que segura um falo descomunal, sob o qual lê-se arma , palavra que significa "armas", "exércitos", mas que também tem fortes conotações sexuais (cf. ADAMS, 1982, p. 16-7); além de emblemática no contexto sabidamente militar da série, é também a primeira palavra do primeiro verso da Eneida de Virgílio (Arma uirumque cano...), poema épico escrito no período seguinte retratado pela série, matéria da segunda temporada de Roma. Tem-se, por isso, uma saborosa antecipação que se estabelece por relação intertextual com o leitor douto.

O travelling pelas ruas de Roma leva o olhar do espectador a dobrar uma esquina, onde há novos passantes, até mergulhar nas camadas ocultas da área de uma parede quase sem cor nem desenho, para revelar um cena mitológica: uma multicolorida medusa que transforma uma figura masculina em pedra. Segue-se novo corte e aparece uma figura humana com as mãos ou pulsos perfurados e vertendo sangue pingando; logo depois, duas figuras, uma laranja e imprecisa, outra, azul: um velho encarquilhado, portando manto vermelho e um caduceu, abaixo do qual se lê a forma acusativa mortem ("morte"), sugerindo que o velho seja, talvez, Hermes-Mercúrio, em seu aspecto psicopompos, o deus que conduzia as almas até o inferum, o mundo subterrâneo para onde se acredita fossem os espíritos dos mortos. Novo corte; agora, uma cabeça masculina, ao lado da qual se lê uitam, a forma acusativa de "vida", explode em sangue para revelar uma jovem mulher nua, nascida da cabeça-ovo. Além do reforço do exotismo das figuras mitológicas e de divindades antigas, o par vida uersus morte instaura-se claramente como temas a serem perseguidos pela série. Talvez seja essa também a sugestão da cena seguinte, em que uma serpente salta dos ramalhetes de flores da carroça de um vendedor para fixar-se como decoração parietal, pois a serpente representava a força vivificante da terra.

As últimas cenas da sequência de abertura são, talvez, as mais impactantes: nas faixas vermelhas - e é preciso atentar que o vermelho sempre foi emblema de poder na cultura romana - dos arcos de um pórtico, aparecem: a) no arco do primeiro plano, a mítica loba romana que amamenta os bebês Rômulo e Remo; b) no arco intermediário, uma cabra que lambe os gêmeos, o que sugere que eles já foram encontrados pelo pastor Fáustulo e sua mulher Aca Larêntia, que os criarão; c) no arco do fundo, uma cena de batalha estática, com soldados armados provavelmente pilhando uma cidade consquistada, em que um soldado animado chuta um inimigo caído, o que evoca o famoso Vae, uictis! ("Ai dos vencidos"). Em suma, nessa sequência aparece condensada toda a história lendária da fundação de Roma, das humildes origens pastoras às glórias militares. Logo depois alternam-se, em rápida sucessão: um mosaico de rua em que foi representada a cabeça da górgone Medusa, com as serpentes que traz em lugar dos cabelos projetando-se por sobre os passantes na rua; uma fonte d'água em forma de cabeça de leão entalhada em bronze, figura do mundo real e estática, e o sol entrevisto na perspectiva da parede lateral dessa fonte; os paineis do calendário do Fórum, sucedendo-se em ordem reversa, terminando em februarius ("fevereiro"), mas iniciando a partir dos meses sextilis e quinctilis, i.e., o sexto e o quinto meses, renomeados para agosto e julho respectivamente, por homenagem a Octaviano Augusto e Júlio Cesar, que serão as principais figuras políticas da aristocracia romana representadas na série, a partir do fio narrativo conduzido pelas personagens de Voreno e Pulo. O encerramento se dá com a palavra $R O M E$ ("Roma") surgindo sobre um reboco de parede vermelho, como a sugerir sangue e 
força das armas que gravaram a fogo o nome de Roma na história do Ocidente, recoberto, por fim, pelo enegrecimento do tempo.

Além disso, seria preciso considerar também dos movimentos de enquadramento do tipo aberto $\mathrm{X}$ fechado, postos em paralelo com os movimentos expansão $\mathrm{X}$ condensamento das sequências de abertura, bem como a condução do movimento pelas ruas da Roma cênica, que leva o olhar do espectador ora para a direita, ora para a esquerda, ora para diante, ora para trás, ora em "rasantes" de superfície, ora em mergulho para dentro de certos objetos, como o crânio do mosaico Memento mori inicial e as camadas de uma pintura que revela uma profusão de grafitos, fixados em tinta já gasta, sobre uma das paredes por onde passa o travelling de abertura da série. Esse movimento, que reitera a figura emaranhada dos caminhos das ruas da Roma mostrada nos créditos iniciais, procura recriar no leitor, como efeito de sentido, a experiência da espacialidade experimentada em um labirinto, metáfora complexa, que pode servir tanto de índice para a profusão de dados de cultura material eficientemente recriadas na série, como os meandros lacunares da história antiga, também recriados pela estratégias narrativas do roteiro, como, ainda, os múltiplos caminhos e descaminhos trilhados pelos protagonistas e principais figuras políticas da série.

A própria palavra Roma, aliás, também recebeu tratamento semiótico nos créditos de abertura da série, de forma a comportar variados índices de significação. A palavra "Roma" aparece em letras semi-ocultadas, na primeira imagem da sequência de abertura, qual seja, o mosaico Memento mori: o leitor interpreta com facilidade e de imediato a trave superior da figura - o nível - de onde pende o peso - a caveira - como um claro e indiscutível "A"; a roda também pode ser percebida imediatamente como um "O"; entre ambos, a meio caminho de uma reta semi-esboçada pela corda do nível, unindo o "A" ao "O" ou vice-versa, a cavidade que há no lugar do nariz da caveira tem forma de "M"; há uma falha no mosaico original (hoje sob a guarda do Museo Acheologico Nazionale de Nápolis, como já se disse), em torno do contrapeso esquerdo, que representa a riqueza, efeito do tempo que fez desaparecer as pastilhas que formam o fundo da figura; entretanto, o artista de Roma "restaurou" o desenho, reconstituindo o laço de uma fita que aparece no original, mas fazendo sua alça mais aberta, de modo a sugerir a forma de um " $\mathrm{R}$ "; por meio desse artifício, induz o olhar a interpretar primeiro e facilmente o "A", na extremidade superior da imagem e, partir dessa expectativa de interpretação e formação de sentido, encontra facilmente o "O", na extremidade inferior, e, com esforço moderado, reconhece o "M", no centro; com um empenho um pouco maior, descobre o "R" no centro, à esquerda, completando o sentido.

As "pontas" se fecham quando, na última cena da sequência inicial, surge claramente a palavra $R O M E$, em elegantes caracteres parietais romanos, com seus traços retos e serifados, figurando tal qual um selo de autencidade, efeito gerado também pelo código cromático de que já se falou, ou seja, os caracteres enegrecidos sobre o fundo vermelhoqueimado, marcas inegáveis da presença histórica e da imensa passagem do tempo, marcado pela experiência da civilização romana sobre o mundo e a cultura ocidentais.

Com tal profusão de signos e referências intertextuais, a animação da abertura de ROMA sugere origem e integração histórica da série, cuja proposta é revivificar o passado da Vrbs. O passado romano é feito de rastros e traços semi-apagados, de indícios imprecisos, de lacunas que indicam traços de vida, mas que, postos em movimento pela empreitada da HBO, resgatam a vida, os acontecimentos, os costumes e a própria cidade, cujos passantes emergem, de início ainda enevoados, a partir da animação das pinturas e grafitos. $\mathrm{O}$ formato de grafito sobre as paredes da cidade é emblemático, já que evoca o intertexto arqueológico da principal fonte para o conhecimento justamente dos aspectos mais quotidianos da vida da Roma antiga, aspectos que a série propõe-se a mostrar com a maior vivacidade possível. $\mathrm{Na}$ 
sequência de abertura fica sintetizada a mensagem de Roma da HBO: a minissérie de TV propõe-se como a nova forma da arqueologia moderna no início do terceiro milênio e, relativizada a pretensão do discurso, a Roma que dali emerge pode não equiparar-se à Roma histórica em todos os detalhes, mas estabelece-se pelo efeito de sentido verossimilhança, produzido pelo apuro das técnicas variadas que se entrecruzaram para produzi-la.

\section{Vsque ad mala (Até o final)}

O fio condutor da narrativa está centrado principalmente nas personagens Tito Pulo e Lúcio Voreno. Tal escolha nada tem de aleatória, antes, produz efeitos narrativodiscursivos bem delimitados, tais como o de gerar uma impressão de que o espectador acompanha os sucessos pelo viés do homem comum, que permite apreender os mais proeminentes fatos históricos da política e da alta aristocracia do ponto de vista de seu impacto sobre o povo. Ambos os protagonistas apresentam-se também como dois aspectos de uma mesma personagem que, em certos momentos encarnam a própria ROMA, ou seja, como equivalentes da velha República (Voreno) e do "homem novo" do futuro império (Pulo).

A figurativização de tais aspectos fica mais eloquente e patente que nunca na cena final de Roma season 1, quando se vêem sequências em corte e alternadas, que mostram Voreno ajoelhado, transido de dor, enquanto toma nos braços o corpo sem vida de sua esposa e, em contraste com ele, os últimos momentos de vida de César na reunião do Senado, prostrado, sangrando pelas inúmeras apunhaladas impingidas por seus colegas senadores. Trata-se da própria República romana que está moribunda e, assim, Voreno também a encarna: morre César e, com ele, a república, o que levará os cidadãos comuns a anos de sofrimento e lutas fratricidas.

A sequência final, por outro lado, mostra Pulo e sua amada, em meio ao campo, cultuando o altar rústico de alguma divindade agrícola, após o que se levantam e caminham pelo bosque em direção à luz difusa de uma aurora que se anuncia por entre as brumas. Trata-se evidentemente de uma representação simbólica do futuro que virá com a ascensão ao poder de Octaviano Augusto, que, após vencer seus opositores na guerra civil, tornar-se-á o primeiro imperador romano e proporcionará aos cidadãos o período conhecido como pax Romana, caracterizada, entre outras coisas, pela retomada de valores ancestrais do mundo da Roma antiga, como o louvor das coisas rústicas, dos pastores e agricultores, dos campos, etc. O próprio Pulo, aliás, encarna a rusticidade em seu temperamento, o que torna muito palatável e adequada a cena proposta.

Por esses e muitíssimos outros cuidados de produção, sofisticações de roteiro e representações cênicas, Roma season 1, embora produzida para ser veiculada de forma seriada na TV, e, por isso, atender ao gosto da grande massa consumidora desse tipo de produto, é uma produção fílmica que supera, em muito, a média das produções do mesmo naipe, inserindo-se, provavelmente, entre as grandes produções cinematográficas, que primam pela capacidade de realização artística daqueles que as engendraram. 


\section{REFERÊNCIAS}

CAESAR, C. I. De Bello Gallico C. Iulii Caesaris: Commentarii Rerum Gestarum. Vol. 1, ed. O. Seel, 1961. In: PHI 5.3. Latin texts and Bible versions. The Packard Humanities Institute, 1991. CD-ROM.

COOKE, B. Caesar's soldiers: the pietas of Vorenus and Pullo. In: CYRINO, M. (org.). Rome, season one: history makes television. $2^{\mathrm{a}}$ ed. Malden, MA (USA)/Oxforf (UK): Blackwell, 2009. p. 78-86.

CYRINO, M. S. Introduction. In: CYRINO, M. S. (org.). Rome, season one: history makes television. $2^{\mathrm{a}}$ ed. Malden, MA (USA)/Oxforf (UK): Blackwell, 2009. p. 1-10.

ECO, U. A inovação no seriado. In: Sobre os espelhos e outros ensaios. Trad. Beatriz Borges. Rio de Janeiro: Nova Fronteira, 1989. p. 120-139.

HAYNES, H. Rome's opening titles: triumph, spectacle and desire. In: CYRINO, M. (org.). Rome, season one: history makes television. $2^{\mathrm{a}}$ ed. Malden, MA (USA)/Oxforf (UK): Blackwell, 2009. p. 49-60.

HBO/BBC. Roma (Rome, the complete first season). Caixa com 6 DVDs. Fabricado sob licença da Warner Bros. Entertainment Nederland (WBEN). Manaus: Microservice Tecnologia Digital da Amazônia, 2006.

HELLER, B. Foreword. In: STAMP, J. Rome. Foreword by Bruno Heller and designed by Stephen Schmidt (Duuplex). New York, NY (USA): Melcher Media in association with HBO, 2007. p. 6.

PEÑUELA CAÑIZAL, E. Tessituras oníricas em Morangos Silvestres. In: PEÑUELA CAÑIZAL, E., CAETANO, K. E. (orgs.). O olhar à deriva: mídia significação e cultura. $1^{\mathrm{a}}$ reimpr. São Paulo: Annablume, 2004. p. 11-67.

STAMP, J. Rome. Foreword by Bruno Heller and designed by Stephen Schmidt (Duuplex). New York, NY (USA): Melcher Media in association with HBO, 2007. 